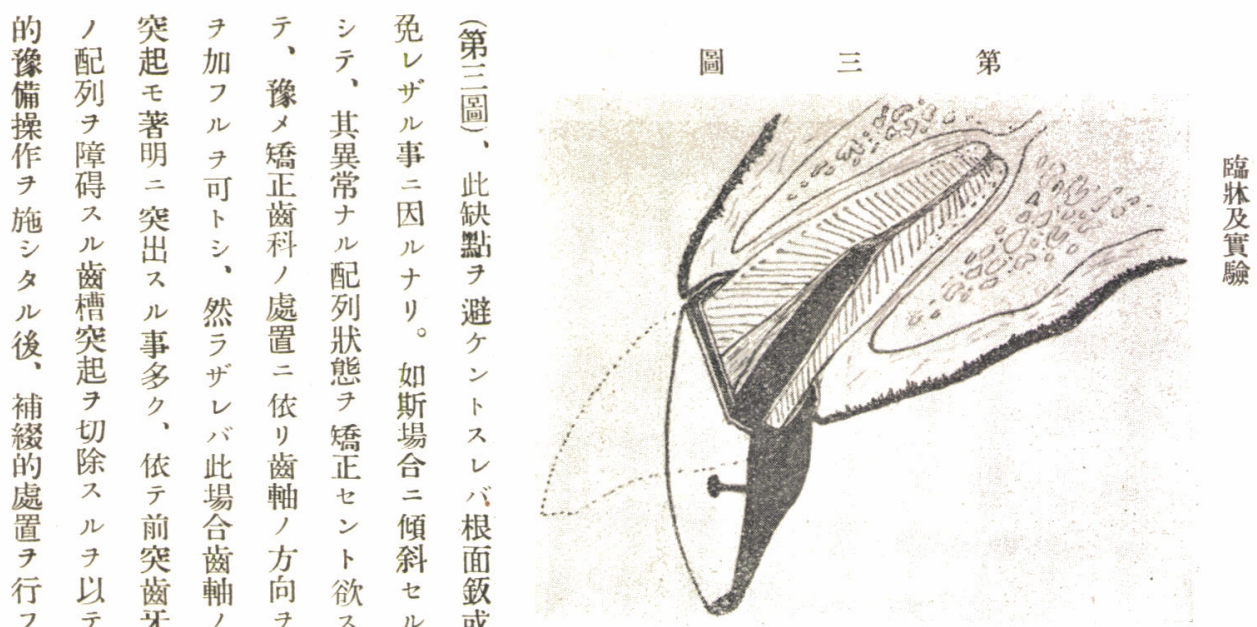

テ牙, 7 ス 或

事有, 傾正儿齒八

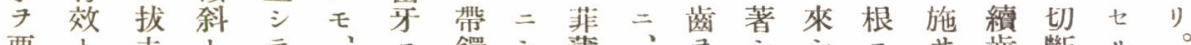

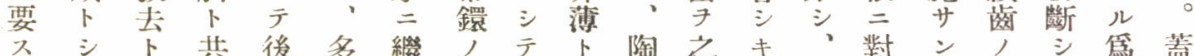

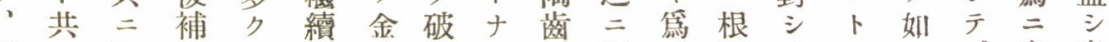

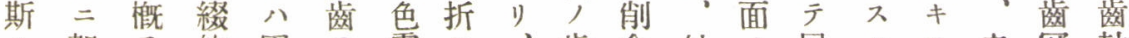
儿架子的困子露シ ’齒合外, 屈儿モ之冠軸 外橋齒 處難裝出易脆頸 ス裝傾曲モ, 二部傾 科齒槽置二置 7 弱端儿陶斜 7 齒 7 繼 7 斜

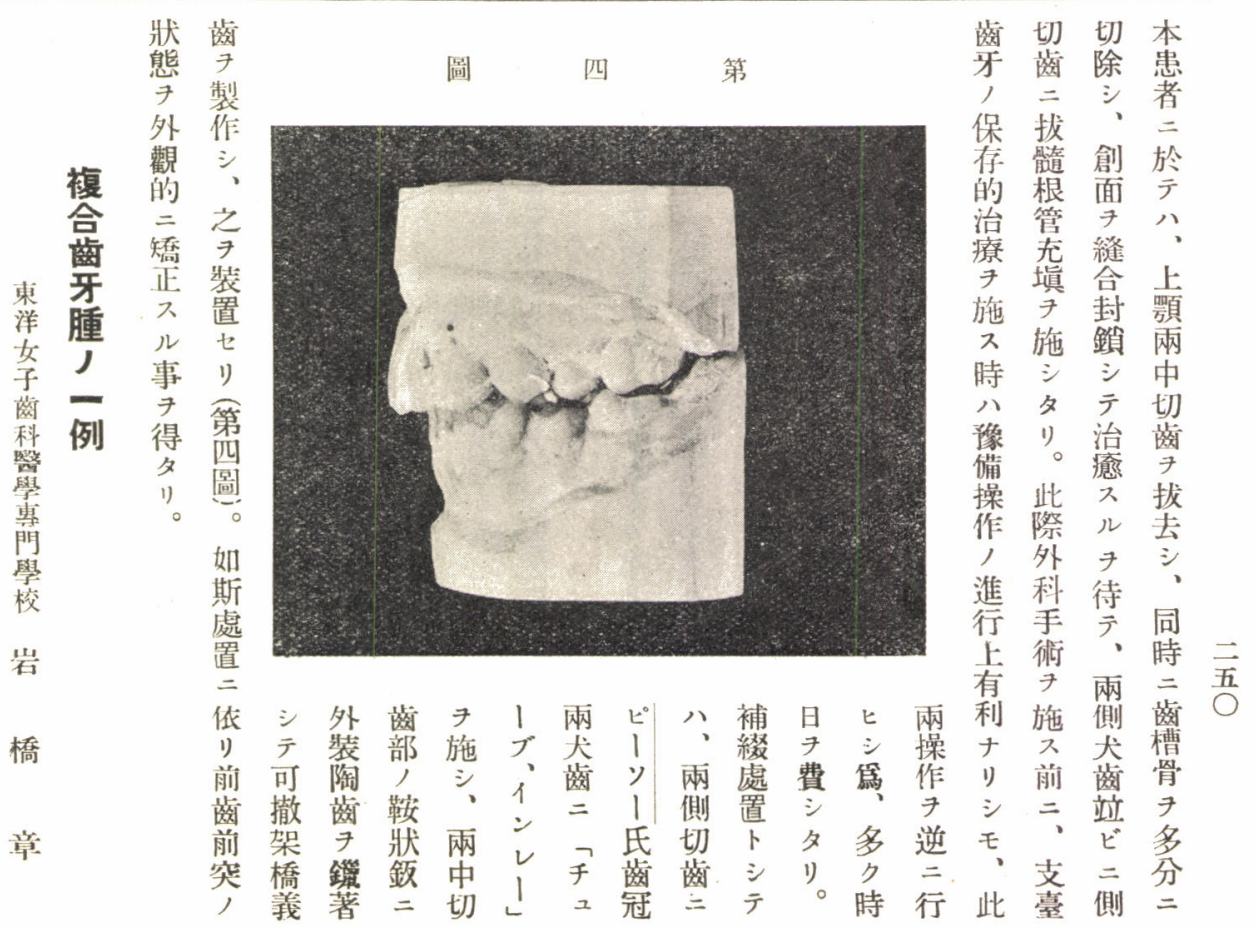




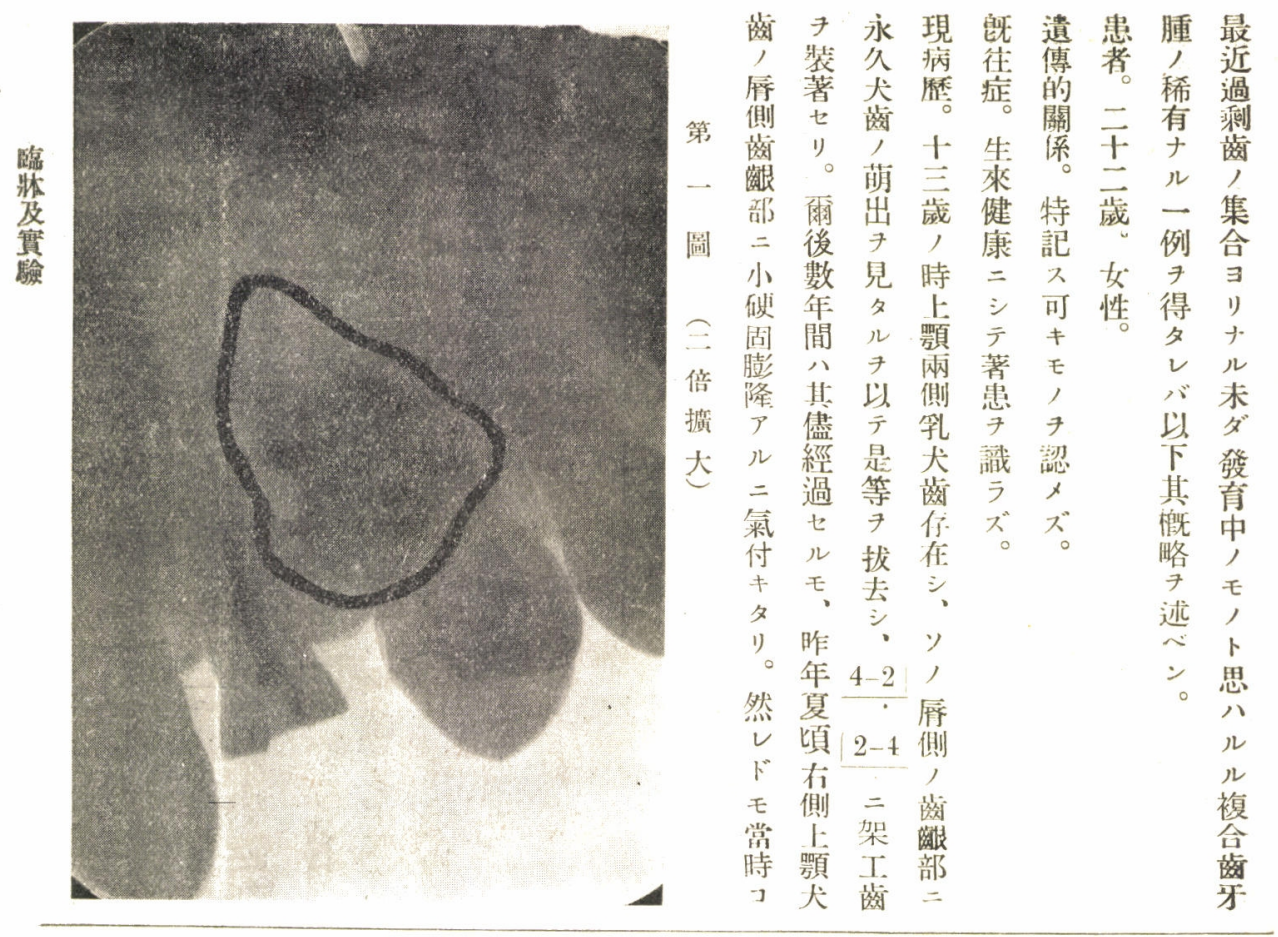

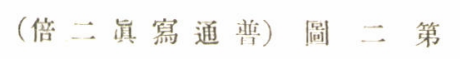

a

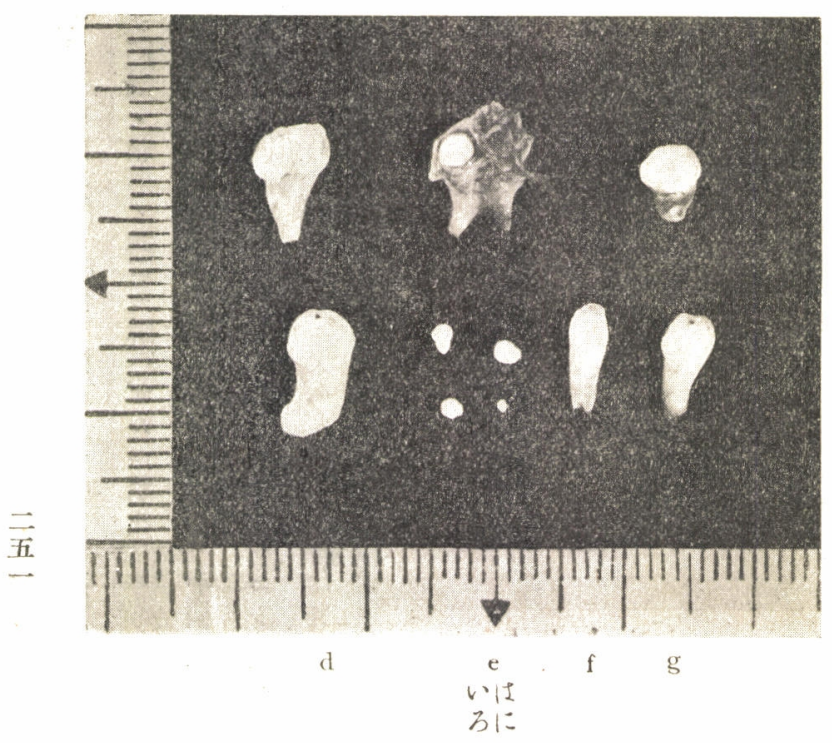

現夆鼻, シ $、$

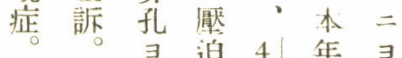
初右り樣, 公产 診側稀感拔月市 上箱 7 髓、特 九 顎 鼻覺 二右別 月犬汁工力側, 八龄, '力上支 日 部流時 碩障 。膨出々 榮隆子䫖卜記來 養罗顬七架サ 體ル部シ楽ザ 格 二 二 二亚り 共至瓦九媱 シ 二 $ル$ 月对 中り神始改以 等 。經 $x$ 造 天 度痛二

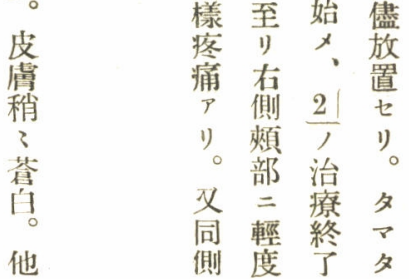




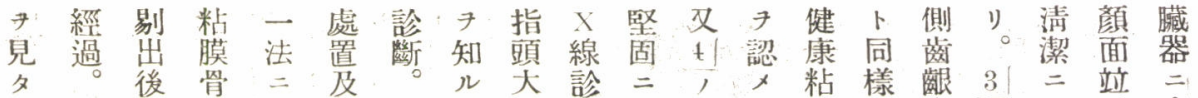

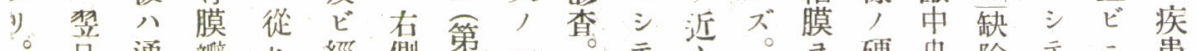

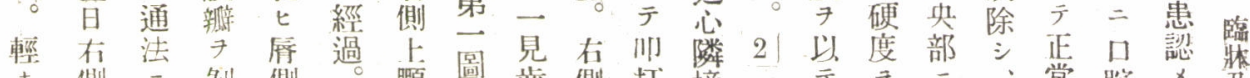

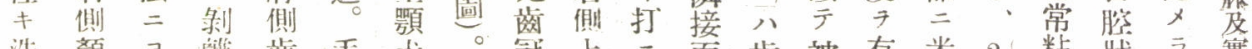

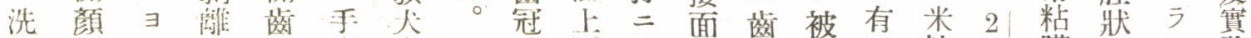

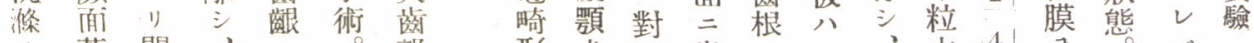

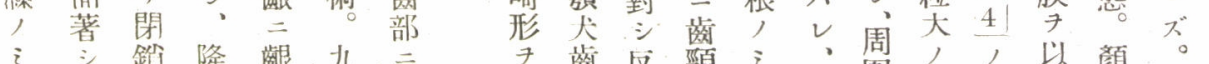

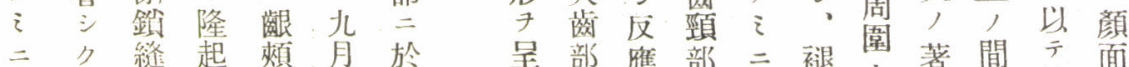

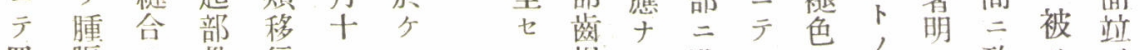
罢脹 ス。

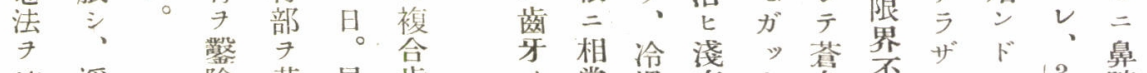

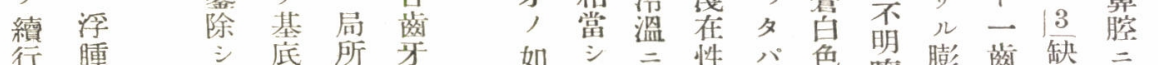

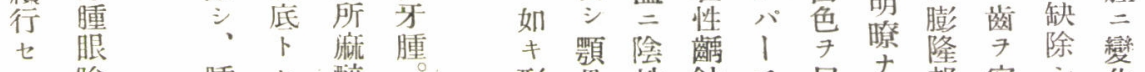

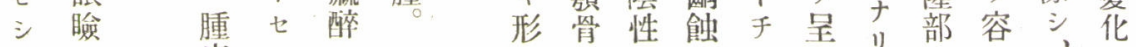

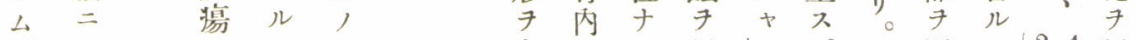

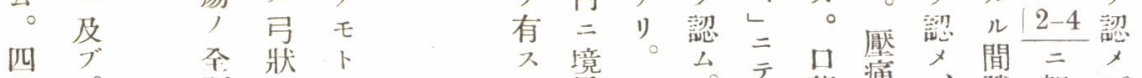

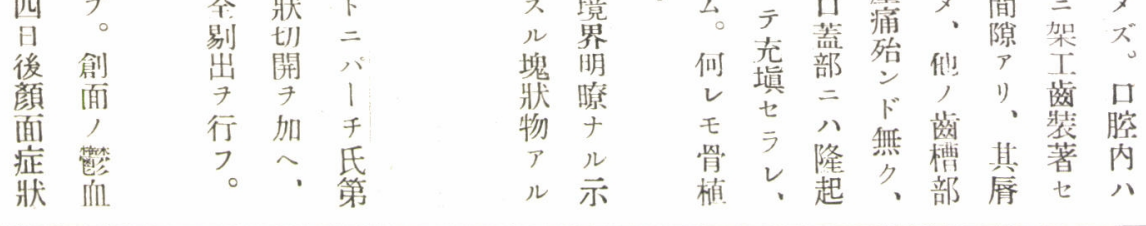

\section{(牛倍二像線光 $\mathrm{X}$ ) 圖三第}

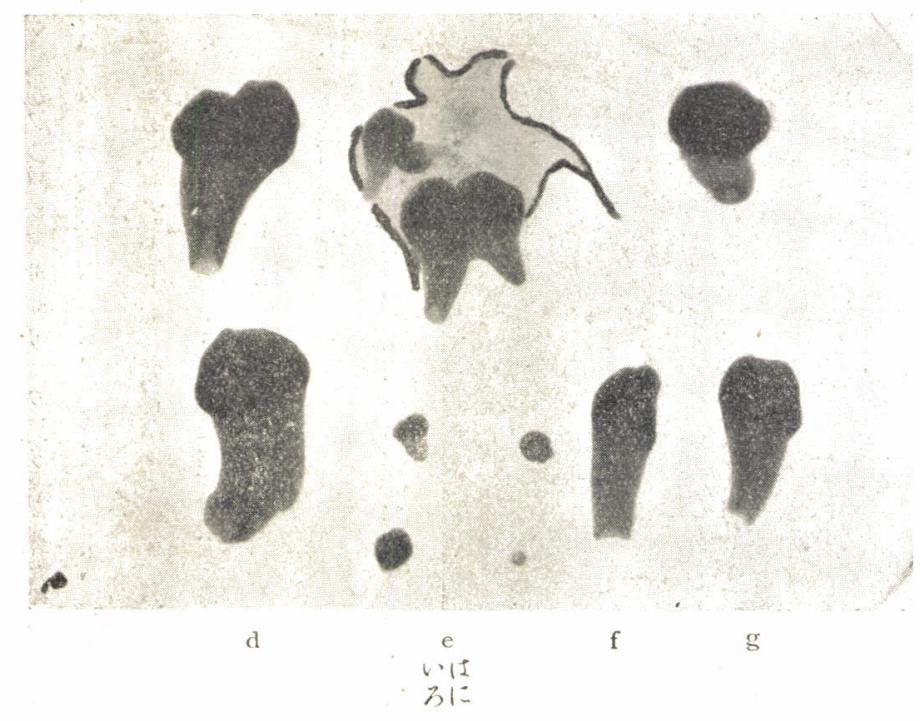

F モ 病後全 以, 理 一, 㕣組週 沙 被示織間失 八指 學 7 久 儿頭的經 。大所過五. コ, 見 シ 日 ᄂ四該 目 子 個肉部創 解, 眼, 面 體突的鈍, 七起端重 癒 二有二訴 7 大入 $\mathrm{X}$ 人 見 小儿光ザタ 九不線儿ル

個整的二

棈 所至以

中圓見ル。テ、五

会橧手拔

七 シ 術絲

儿テ時 七

モ繊剔紧。

, 維 出

第 性 七

二囊 ル

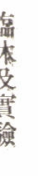




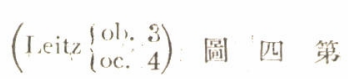

$\mathrm{S}$

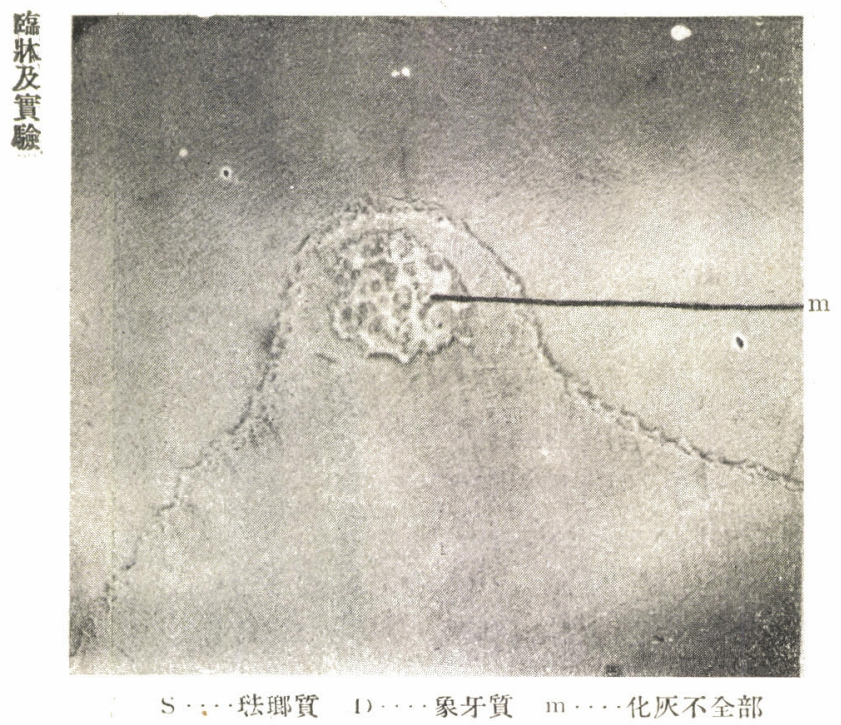

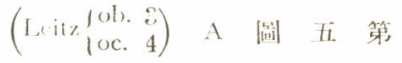

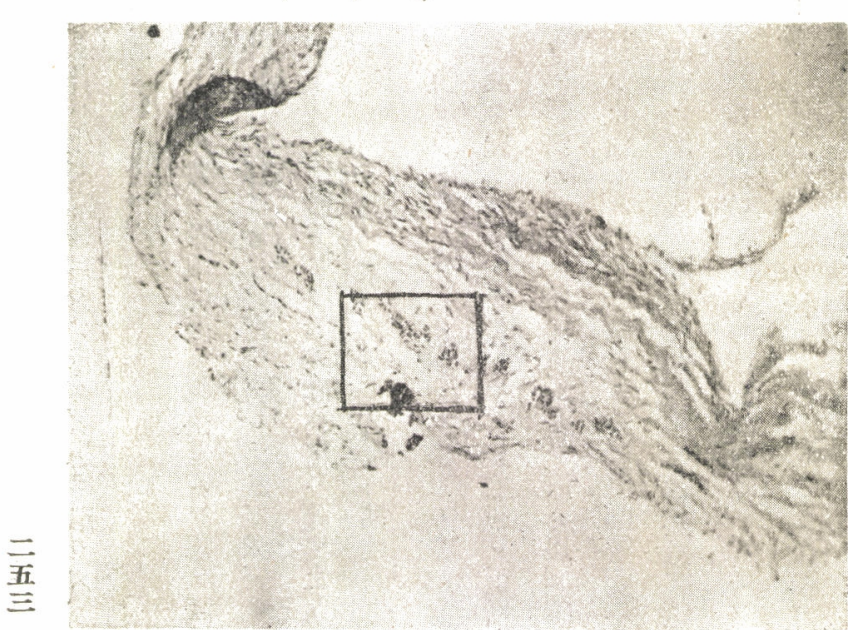

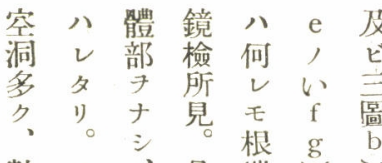

數y? 是立耑 $\mathrm{g}$

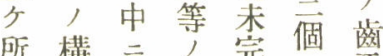

喥齒齿而成, 牙

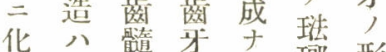

扊正 7 八リ珢形

不替包冠第球熋

全ノ藏頭忽見具

部モ主珐高置具

認卜 根質。リ七

メ變部年第

タリ心以云,

リ十菲テ被薄・

第 、㴰 被高第

四唯

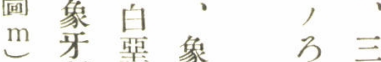

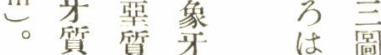

㐫質比

罍二以八 b

牙球示, 落 c

八齒在患隔八包

其牙口者子結藏

, 膑八以締七

構形内受テ織ル

造態二診上細鸾

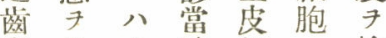

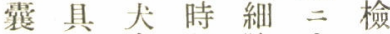

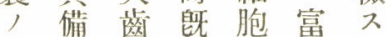

ソ七嵌二群界ル

ᄂ $几$ 外乳, 、

卜本, 心存内荀

一完缺齒 在 愿 营

致成除, 久,

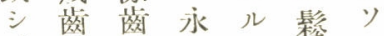

、現 人

處八見犬視結卜

々レズ邺夕夕締異

二、・ リリ織ナ

步是手拔 第

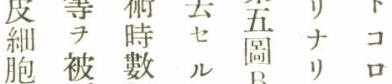

群 覆 個塊, 處土

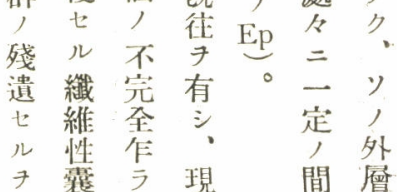




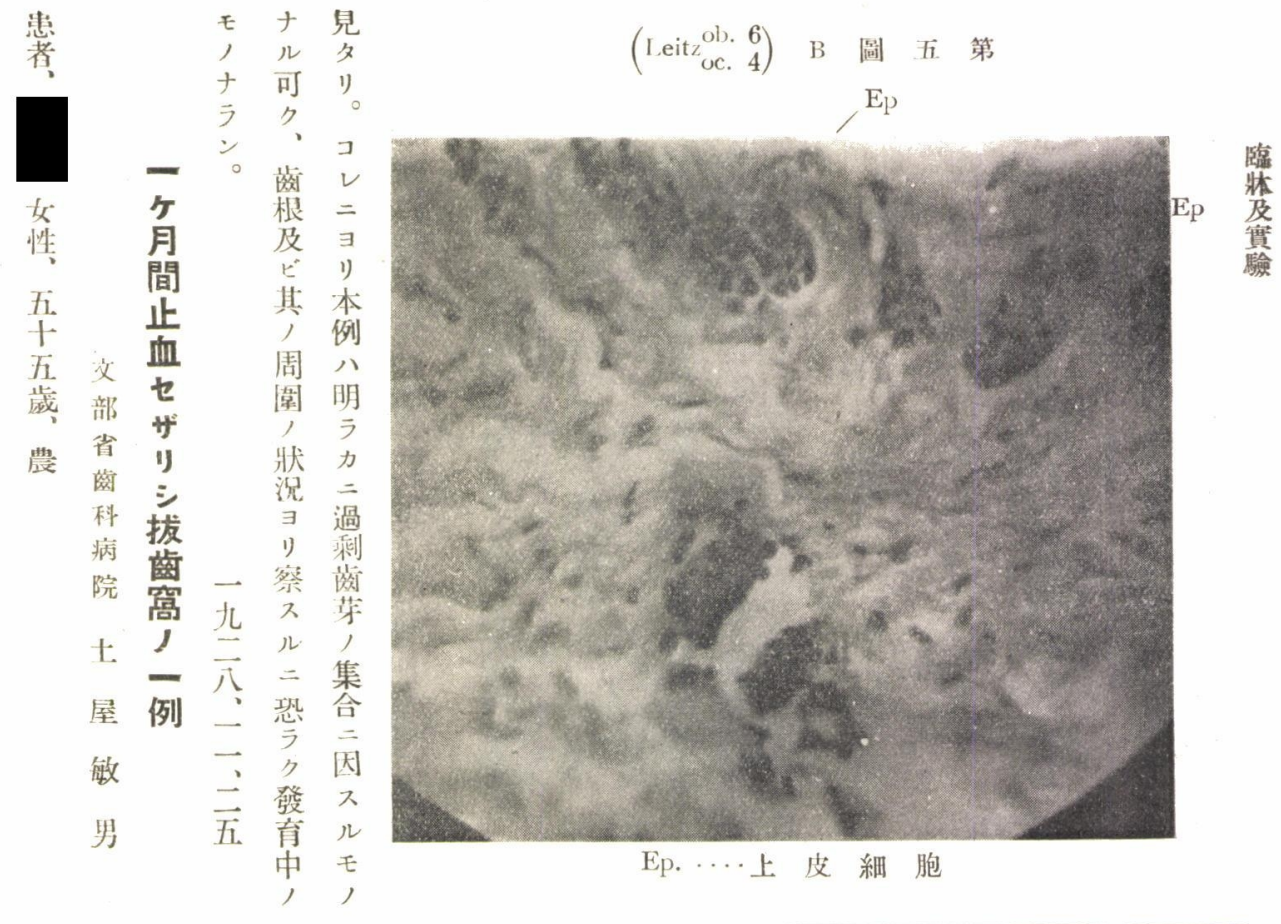

モ此々。血其焦山。リ 心睢。七中躁。經 7 診ラ 止卜部去年テ往

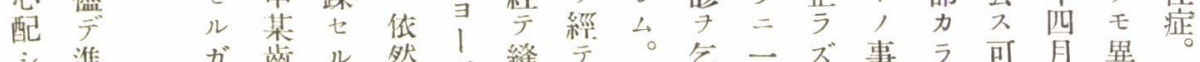

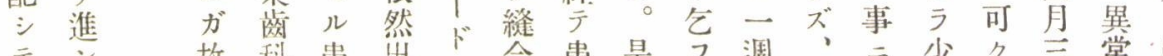

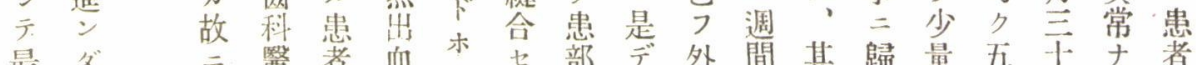

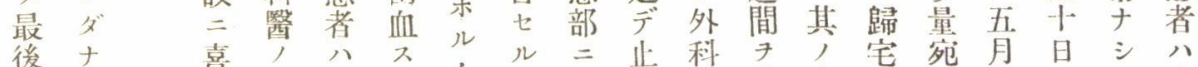

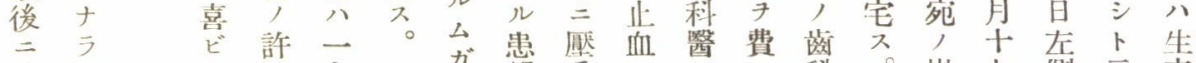

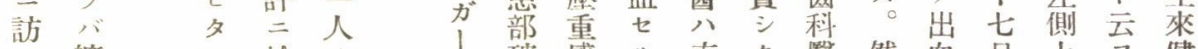

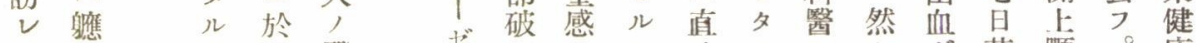

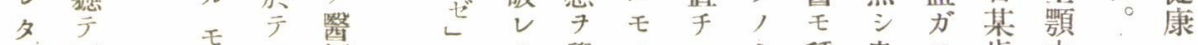
, 死束 ガ 師 ガ , 只二 淺致間ゼ滿 草ル デし 足 某ア數虫 ズ 院ウ 間 部 內

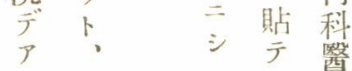

虫者 元 押齿

夕者元押齿

此 ビ 狀 所䣽 處近親態漸轉 是, 歸夕夕

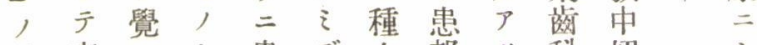
栓尔工ト患デ々部 ツ科切 シ

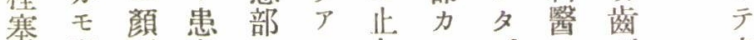

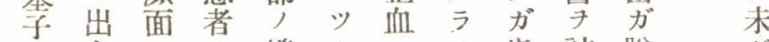

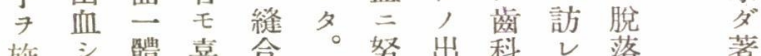

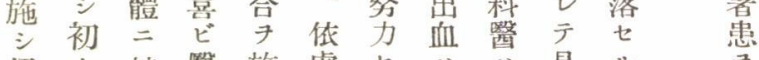

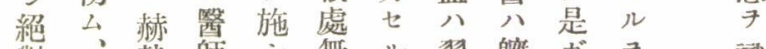

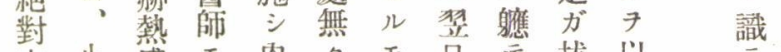

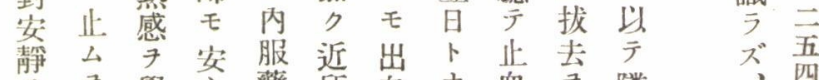

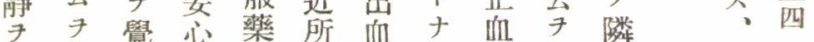
命得 于綘一處人科剛依故夕ル的 歸合時、テ酢二然心。殘關 八者紧止 三 ラ 間 數 歸) シ ト配其根係 シ 取程時宅許テシナ際 7 二 